\title{
Can Asset Markets Be Manipulated? A Field Experiment with Racetrack Betting
}

\section{Colin F. Camerer}

\author{
Califormia Institute of Technology
}

\begin{abstract}
To test whether naturally occurring markets can be strategically manipulated, $\$ 500$ and $\$ 1,000$ bets were made, then canceled, at horse racing tracks. The net effects of these costless temporary bets give clues about how market participants react to information large bets might contain. The bets moved odds on horses visibly (compared to matched-pair control horses with similar prebet odds) and had a slight tendency to draw money toward the horse that was temporarily bet, but the net effect was close to zero and statistically insignificant. The results suggest that some bettors inferred information from bets and others did not, and their reactions roughly canceled out.
\end{abstract}

\section{Introduction}

-This paper reports an unusual field experiment that attempts to ma nipulate prices in a naturally occurring asset market: pari-mutuel betting on thoroughbred racing. The experiment addresses two questions: First, can markets be manipulated? Second, what does the effect of attempted manipulation tell us about the way prices in cen-

Research assistance was provided by Jessica San-San Tien, Dov and Amanda Rosenberg, Hongjai Rhee, Angela Hung, and Chris Anderson. Excellent secretarial work was done by Gail Nash. Helpful comments were received from participants at the MacArthur Foundation Preferences Group, the Russell Sage Foundation Behavioral Economics Summer Camp (Berkeley, July 1996), the Harvard Behavioral Economics Workshop, the Economic Science Association (September 1997), Peter Bossaerts, Tim Cason, editor Lars Hansen, Teck Ho, Hongjai Rhee, Charles Plott, Simon Wilkie, and an anonymous referee. Early preparation was provided by Rich Palmer and Burt Camerer (who taught me to ask "why is that?"). 
tralized asset markets reflect the aggregated information held by traders?

These questions have fascinated economists and other social observers for a long time. The answers are of practical importance because much of the case for the social value of organized asset markets-particularly for derivative assets such as options, stock indexes, and so forth-rests on the presumption that markets cannot be easily manipulated (so small investors are not routinely bilked by large ones). While most cconomists probably do not believe that market manipulation is widespread, many small investors do. The ability, or inability, to manipulate a naturally occurring market in a controlled experiment provides rare evidence of the feasibility of manipulation.

A further claim is that information about important financial data is better conveyed if these derivative markets exist than if they do not, because prices aggregate information. It follows that if these markets do not aggregate information well, perhaps they should not exist. The ability to manipulate the market provides indirect evidence about information aggregation.

\section{A. Information Aggregation}

There is much more theory about aggregation of information than there is careful observation. The standard theoretical claim is that information could not be perfectly aggregated and revealed by prices because, if it was, no traders could profit from collecting information (the "Grossman-Stiglitz paradox"). A corollary principle follows logically: If prices are a noisy reflection of what people collectively think assets are worth (e.g., because of exogenous shocks in the supply of shares or trading for liquidity), then the benefit to collecting information is restored, traders will pay to dig up information, and prices again have something to aggregate (but can do so only imperfectly).

Meanwhile, a decade or two of very careful, persistent experimental observation has proceeded in a one-sided dialogue with theory (see Duxbury [1995] and Sunder [1995] for reviews). In a typical experiment (e.g., Plott and Sunder 1982), traders are given free information about asset values. Usually traders have different information, which is collectively perfect about the underlying asset value. When asset values take on two or three different values and assets live just one period, information aggregates nicely so that the price that results from trading based on private information is close to the price that would result if everyone revealed his or her own information to others honestly. When information structures are more complicated, information aggregates less smoothly (see Sunder 1995). 
Thus the cumulation of 20 years of theorizing and a similar span of experimental observation is that nearly perfect aggregation is a theoretical possibility that is commonly observed in simple experimental environments but rarely observed in complex ones.

Another strand of related literature is studies of stock market reactions to large-block trades. Scholes (1972) established, contrary to the conventional wisdom of the time, that prices drop slightly when large blocks ("secondary distributions") are traded because the market thinks that the sale reveals bad news (not because of temporary price pressure). Dann, Mayers, and Raab (1977) showed that the adjustment of prices to the perceived bad news happens quickly, in minutes. Since the temporary bets we make are similar to largeblock trades, it is conceivable the betting market would think that they reveal information. If the Dann et al. finding applies, prices would quickly and permanently adjust.

\section{B. Market Manipulation}

For present purposes, define market manipulation to mean trading against one's information or preferences, to create price movements that will lure other investors and ultimately allow later profit. In alleged manipulations of this sort, a firm's managers "prop" up its stock price by aggressive buying and then later sell as investors take the bait and prices rise.

Markets in which some investors try to infer information of others from price signals might be vulnerable to market manipulation of this sort. Manipulators could make uninformative trades that might seem to convey information, but are actually made to deliberately mislead uninformed traders (for the purpose of later profit). There is a modest theoretical literature on this possibility but few data (e.g., Allen and Gale 1992; Benabou and Laroque 1992).

The experimental literature provides both an illustration of how manipulation might work and a little evidence of the vulnerability of markets. Camerer and Weigelt (1991) and Sunder (1992) conducted markets for one-period assets of uncertain value. The number of traders who were (perfectly) informed about the asset's value in each period varied (it was sometimes zero), and that number was not common knowledge. Thus there were periods in which no traders were informed, but no trader knew that (and given their priors, traders thought it was likely that somebody else was informed). In some of these periods in which no traders were informed, subjects sometimes overreacted to trades that were similar to previously informative trades. For example, in one period of trading, subjects had seen the price rise swiftly, and it was later revealed that the asset 
value was high. Then in the next period, a small upward price movement led traders to believe that the asset value was high. These reactions became self-fulfilling, as traders watching the market became increasingly convinced that some other traders must be informed. The result was "mirages" or falsely revealing informational price bubbles (e.g., Camerer and Weigelt 1991; Sunder 1992). These mirages are a theoretical possibility that can be observed clearly in the lab. However, mirages were rare. And in later trading periods of the experiment, after subjects had more experience, there were only temporary mirages-brief strings of self-fulfilling price changes that would self-correct after a minute or so and reverse direction.

In these experiments, there is no evidence that traders were deliberately creating mirages. But since mirages did occur and traders mistakenly became convinced during the mirage episodes that others had information (which was revealed by the prices), the possibility exists that traders eager to infer information from price signals could be fooled by extremely clever traders. For example, Bill Gates could rush onto the floor of the New York Stock Exchange and sell Microsoft shares hysterically-causing astute traders to think that Bill knew bad news, and sell-while his minions buy up shares at depressed prices. On the other hand, rational traders who are aware of the possibility of manipulation might not be fooled by such a display. While this kind of informational market manipulation is sometimes mentioned anecdotally, ${ }^{1}$ it is rarely clearly observed in the wild; hence, any such effects are hard to pin down and evaluate statistically. An experiment that attempts such manipulation under controlled conditions is therefore useful.

An additional goal of this experiment is methodological. Field tests of information aggregation with naturally occurring data are extremely rare because the information held by traders is rarely observed. Since field tests are rare and many experiments have been run that test theory directly, it is surprising that careful observation from controlled laboratory experiments has not influenced theoriz-

${ }^{1}$ There is a well-known story about Nathan Rothschild, who was famous for having the fastest carrier pigeons in London, trading flamboyantly in the (ex post) wrong direction after receiving news about Napoleon in Waterloo, while his agents coverty bought up shares made cheap by Rothschild's ruse. Temporary bets of the sort reported in this paper are apparently common in New Zealand: "It is no secret that pro punters have been artificially suppressing the dividends [odds] of horses they want to back down to levels where the average punter will not invest" ("New Rules Hit Pro Punters," 1997, p. 43). Having displaced money from a favored horse, which "New Zealand punters, unlike Australians, traditionally shy away from," the pros then withdraw most of their bet and allegedly get inflated odds. In an effort to prevent such manipulations, in 1997 betting houses withdrew the right to cancel bets of more than $\$ 200$ less than 15 minutes before race time. 
ing more. One reason for this lack of influence may be that laboratory markets do not have all the features of naturally occurring markets, which makes one cautious in generalizing from the lab. (Of course, features can be added to experiments, if theory predicts that they will matter.) This paper simply circumvents the concern about generalizability by providing evidence from a true, controlled experiment in a naturally occurring market.

\section{How This Research Came About}

This research was inspired by two lucky observations.

First, occasional attempts at market manipulation were observed in pari-mutuel betting experiments conducted at Caltech by Plott, Wit, and Yang (1996) (and earlier by Nöth and Weber [1996]). In the Caltech experiments, subjects are given private information about which subset of events contains the true event. Different participants have different information (different subsets), and the true event is always contained in the intersection of the subsets (sometimes uniquely). For example, suppose that the events are labeled $A-F$ and the true event is $C$. Then some subjects are told that the true event is either B or C and others are told that it is either C, D, or $\mathrm{E}$.

In these pari-mutuel markets, like the racetrack markets, subjects place bets on which event is the true one, during a brief time period with a stochastic end. After the single true event is revealed, those who bet on the true event share all the money bet (plus a bonus, to motivate subjects to trade). On a couple of occasions, participants deliberately bet small amounts of money on events they knew could not have happened. For example, a person who knew that the event was either $B$ or $C$ might bet on $D$, hoping to draw money toward D, which they could collect later by betting on B and $\mathrm{C}$. While there is anecdotal evidence of this sort of manipulation in financial markets, its occurrence in the laboratory raised afresh the question of whether such manipulation is possible in naturally occurring markets (and, particularly, in markets much larger than the laboratory ones).

Second, while using a computerized system at a large horse racing track, I mistakenly canceled a "live" bet on a race not yet run. This mistake revealed the fact-which is not widely publicized-that computerized bets on a race could be made, and then canceled, before the race was actually run.

Putting these observations together, I realized that the attempts at market manipulation made by subjects in the lab at Caltech could be made in the large betting market at the racetrack, because the 
bets could be canceled. Furthermore, the betting could be done in the form of a controlled experiment, with randomized assignments of the betting "treatment" to some horses and a proper "control group" of horses that were not treated experimentally.

So this paper asks the question, Does the potential information in large bets that are made and canceled systematically mislead traders - as the participants in the Plott et al. experiments tried to door does the information aggregation process ignore my temporary bet, much as waves breaking rhythmically on a beach ignore rain from a brief summer thunderstorm?

\section{Research Design}

\section{A. Facts about Pari-mutuel Betting}

Before explaining the experimental design, I need to explain some basic facts about pari-mutuel racetrack betting. Throughout I shall talk about only "win" betting: bettors collect money only if their horse wins the race and lose their bet otherwise. Pari-mutuel betting means that bettors put money on a horse, and if their horse wins they get to keep their bet and also share with the other winners all the money placed on losing horses (minus a fraction the track takes out). Thus bettors are essentially betting against one another rather than against a bookie who has designated odds.

In pari-mutuel betting, bettors may place bets at any time until the race occurs. Suppose that the totals bet on horse $i$ at the time of the race are denoted $B_{i}$ and their sum is $B$. The track takes a percentage of the total bet, a cut that is predesignated and regulated by the state, usually 15-20 percent of the amount bet (for win bets). Then the remaining money is distributed to the winners in proportion to the total bet on the winning horse. For example, if horse 7 wins, those who bet on that horse each get back (.85) $B / B_{7}$ for each dollar they bet. ${ }^{2}$ The "win odds," the fraction or multiple of earnings for each dollar bet, net of getting one's bet money back, would be $\left(.85 B-B_{7}\right) / B_{7}$ if the track takeout is 15 percent. For example, if 25 percent of the win pool is bet on Sandpit, the win odds would be $(.85-.25) / .25$ or $2.4-1$. A bettor who placed $\$ 10$ on Sandpit and won would get $\$ 24$ from the other bettors and win her $\$ 10$ back. Notice that the more is bet on a horse, the lower the odds are. The only odds that matter for payoffs are the final odds established by

${ }^{2}$ On a very heavy favorite, $.85 T$ could be less than $T$, so that bettors get less back than they bet if the formula is applied strictly. In these situations (which rarely occur) the track is obliged to pay a minimum, usually $\$ 2.10$ on a $\$ 2 \mathrm{bet}$, and the track loses money. 


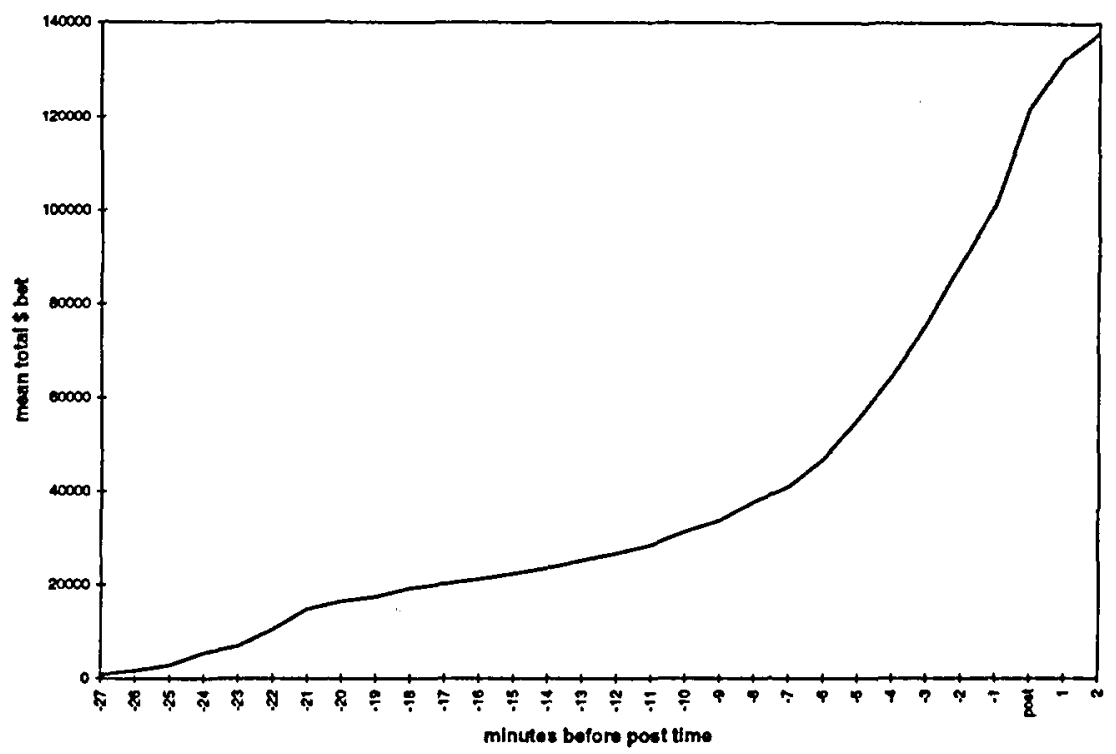

Fic. 1.-Cumulative betting on all horses (mean across all sample 1 races)

the cumulative total amounts that have been bet at the time the race actually starts.

An important feature of this system is that, in contrast to betting with bookies at odds the bookies fix and guarantee, bettors who bet well before post time do not know the precise totals that will be bet on different horses by the time the race begins. Hence, they do not know the odds they will receive if their horse wins. Because of this uncertainty, it is hard to imagine why rational bettors would bet early, since they do not know the "price" they will be getting. Indeed, while many people bet early, the cumulative total of bets does rise sharply as post time draws near. Figure 1 shows a time series of the mean amount of (cumulative) money bet across the races in our first sample; the abscissa is minutes before post time. Notice that about half the money is bet in the last 3 minutes before post time. The fact that this graph looks a lot like the equivalent time series of cumulative betting in the Plott et al. (1996) pari-mutuel experiments is a good example of parallel behavior in laboratory and natural markets.

In the racetracks at which I experimented, the totals of cumulated money bet are displayed on two large "tote boards" in the middle of the racetrack "infield" and also on computer screens throughout the track. Totals are refreshed every minute. This fact is important because it enables one to unobtrusively record a 
minute-by-minute time series of how betting totals are influenced by one's temporary bet. It also means that bettors have ample opportunity to notice the effect of the bet almost immediately.

\section{B. Experimental Design}

The basic design is a simple "matched-pair" design. Each experimental "subject" - a horse that is bet temporarily, in this caseis matched with a comparable subject, a horse in the same race. The matched-pair design is powerful if the matches are close and control for common sources of variation that might otherwise obscure a treatment effect and are not easily randomized away. ${ }^{3}$

In each bet race I chose a matched pair of horses with similar features. The key features are the forecasted "morning line" odds and the initial odds set by early betting. A coin was flipped to determine which horse to temporarily bet on; the other, unbet horse became a within-race control. The time at which a race is scheduled to begin is called "post time" (usually the race actually starts 1-4 minutes later, and bets are taken after post time, up to the very moment the starting gate opens and the race begins). The temporary bets usually were made 17-22 minutes before post time (after about 3 minutes of betting had taken place), and the bet cancellation came 5-8 minutes before post time. The bets took about 30 seconds to make and cancel, so the effects of bets and cancellations sometimes appear on the tote board in 1-2-minute intervals around the official bet/cancel times I recorded. In the first sample, bets were $\$ 500$, which, as we shall see, is enough to move the odds on the attack horses noticeably. (If the effect of these bets proves too small, the bet size can be adjusted upward in further experiments, as in a second sample reported below.)

\section{Criteria for Experimental Treatment}

Data were collected from three tracks in spring 1996. Races were chosen for experimental bets if they had all of the following features.

${ }^{3}$ The matched-pair design is useful when observing control subjects is expensive or treatments are naturally' scarce (as in some medical experiments with rare symptoms). Then randomized allocation of subjects to a control condition does not provide large enough samples to guarantee that uncontrolled differences between treatment and control subjects "cancel out," in the sense of the law of large numbers. Matching control and treatment subjects on as many potentially relevant variables as possible is then a better way to statistically detect the treatment effect. The ultimate example is a "twin study," widely used to compare genetic and environmental variations, in which identical twins raised apart, e.g., constitute a pair matched for genetic factors. 
a) Two horses in the race have exactly the same "morning line odds," "from 8-1 to 50-1. I chose these relative long shots so that a $\$ 500$ bet could move their odds dramatically. In 15 cases, three horses were used (and in two cases four were used), with one serving as the temporary-bet horse and an average of the other two or three serving as a composite control horse. These composite controls smooth out variation in the control and improve test power.

b) Within 1-4 minutes of the initial display of betting totals and before the temporary bet occurs, the two horses must have initial betting totals within 25 percent of one another (the minimum of the two percentage discrepancies was used). In many cases the morning line odds were the same, but this condition was not satisfied because horses with similar morning line odds often opened with very different amounts of money bet on them (and, hence, different opening odds).

c) A temporary bet must be comfortably made around the window 19-23 minutes before post time for "live races" (where bets were made at the track at which the race was physically run) or 17-20 minutes before post time for "remote races" (where bets were made at one track on races televised at the track but run elsewhere).

In the course of several months, gathering data carefully according to criteria $a-c$, I made a total of 50 temporary bets and recorded the minute-by-minute bet totals.

\section{Theory}

Before I turn to the results, it is worth working through some informal theoretical arguments about the conditions under which these markets might react to my attempted manipulation, and in which directions. It is important to point out at the start that some bettors may earn their living by wagering, but the (dollar-weighted) average bettor loses because the track's takeout ensures that betting has a negative expected value. Thus it is not clear why expected utility maximizers would bet at the races. They might be risk-preferring in the classical sense (their utility function for money is convex), though I do not think that this is the full explanation. ${ }^{5}$ They almost

\footnotetext{
${ }^{4}$ The morning line odds are a forecast by a handicapper employed by the track of what the post time odds are likely to be. Matching on morning line odds matches horses for any unobserved ability or characteristics (jockey or post position) thought by the track handicapper to influence the eventual odds.

${ }^{3}$ For example, an expected-utility-maximizing person betting a horse to win, and believing that the odds are fair, must have convex utility. But occasionally two horses finish the race almost exactly tied, and it takes several minutes for the track stewards to examine a photograph and declare a winner. Sometimes they cannot decide and declare a "dead heat": people who bet on either horse share the money bet by all others. These dead-heat payoffs are obviously lower than if any single horse had
} 
certainly think that they are relatively skilled, compared to others, at picking winners. Or they may simply get enhanced consumption value from watching a race they have bet on. It is also mysterious why any bettors would bet early (keep in mind that most do not). Since the money one can win is determined by the cumulative total bet at the time the race begins, the odds are never certain and fluctuate a bit before the race; so betting early just adds an element of price risk that bettors presumably dislike.

Since we do not have a clear understanding of why bettors bet at all, and bet early, it seems inappropriate, or at least too difficult, to create a full-blown theory. Instead, I suppose that bettors come to the track with a preference to bet, some prior opinions about each horse's chance of winning, and some preference for the timing of bets (i.e., some people prefer to bet early and others prefer to wait). Assume that bettors watch the tote board and may use information about bet totals to determine their bets (in ways I spell out below). Then manipulation should have an effect if four conditions hold: (1) Ignorance of cancellation: Bettors must not realize that bets can be canceled at all, or if they know that this is possible, they must think that most bets will not be canceled. (2) Visibility: The bet must affect the odds visibly. (3) Reaction: Traders must react to changes in perceived odds. This is the crucial step in the argument; let me return to it in a moment. (4) Asymmetry: There must be an asymmetry between their reaction to the odds when the bet is placed and their reaction when the bet is canceled.

If the ignorance condition 1 does not hold, bettors will ignore all bet totals until the race is so close that cancellation is not possible. Then our temporary bets would have no effect because, by definition, we cancel them a few minutes before the race. This ignorance condition is likely to hold because canceling is not mentioned in any program information distributed to bettors by the track (and, in fact, is not allowed at most racetracks in the United States). Cancellation also seems to be rare because the bet totals hardly ever fall over time; if bettors were routinely canceling, the totals would sometimes fall. Furthermore, I asked a few bettors whether bets

won (since the win pool is being shared by two sets of winners rather than just one). If bettors have convex utility, then in the tense minutes while they wait for the stewards' decision they should prefer to flip a coin and either win alone or lose than to tie and have a dead heat declared. In my experience bettors always prefer a dead heat. Thus it seems that they "become risk-averse" after the race is over but before a winner is apparent. This strongly suggests that their wagering is not due to convex utility and risk preference, per se. Instead, it is more plausible that they are overconfident about their relative skill at picking winners, but not at their relative skill in guessing the outcome of a dead heat after the race is over. 
could be canceled, and most were quite surprised that cancellation is possible.

If the visibility condition 2 does not hold, the bet simply does not catch their attention. The visibility condition probably does hold because, as the figures below show, the change in odds is fairly dramatic and any bettors who glance at the tote board odds continuously before the race are likely to notice.

If the asymmetry condition 4 does not hold-bettors' reactions are symmetric - then there will be no net effect of the manipulation. For example, a temporary bet might draw other people to bet on the temporary-bet horse when the bet is first made and to bet on other horses when the bet is canceled, and the two effects cancel out. While this would mean that there is no net effect, the two separate effects would be visible in the data since we have a minute-byminute time series of bet totals. The asymmetry condition is likely to hold because a fixed-size bet has a much larger effect on the odds when it is first placed than when it is canceled (as will be seen below), because the win pool is constantly growing over time. Thus, if bettors react to the absolute size of a change in odds, their reaction will be stronger when the bet is made than when it is canceled. In the later argument $I$ assume this form of asymmetry.

The reaction condition 3 is the crucial one. To understand reactions it is helpful to distinguish three possible types of bettors: opinion bettors, partial rational expectations bettors, and full rational expectations bettors.

i) Opinion bettors have an opinion (or subjective probability) about the chances of each horse and do not infer superior information from odds. (Opinion bettors are sometimes called "private-information" investors in theorizing and experimental work.) They compare the available odds with their opinions and choose the most favorable odds relative to their subjective beliefs. When the temporary bet drives the odds down, money that would flow to that horse from opinion bettors is displaced (the bet has lowered the return they can get without changing their opinion of the probability of winning). When the temporary bet is canceled, money from the opinion bettors comes back because the odds are now higher. For example, suppose that my bet lowers a horse's odds from 20-1 to 12-1. Some opinion bettors would have bet that horse at 20-1, but they notice the drop (if there is visibility) and are unaware that the money will be canceled (if there is ignorance), and they therefore bet on some other horse. Assume for the sake of argument that the odds stay at 12-1. Then when the bet is canceled several minutes later, the win pool is larger, so the cancellation has a proportionally smaller effect and raises the odds to, for example, 14-1. Now some bettors who 
are waiting to bet and would not bet the horse at 12-1, but will bet at 14-1, will bet on this horse. Asymmetry assumes that the initialbet effect is stronger than the effect after cancellation. Assuming visibility, ignorance, asymmetry, and reaction by opinion bettors therefore implies that the temporary bet will displace more money than the cancellation will draw, so the difference in the bet totals between the temporary-bet horse and the matched control horse at post time will be negative.

ii) Partial rational expectations bettors believe that bet totals contain information and also believe that others do not fully adjust to the information. (For example, they could believe that many others are opinion bettors.) There is much evidence that at least some bettors do react to price signals in this way. For example, the Daily Racing Form, which contains detailed information on past performances of horses and advice for bettors, often says "watch the tote board" for fluctuations in odds of horses that have not raced before, not raced recently, or raced at a distant track. Presumably people pay for this advice, and sometimes follow it, because they think that everybody else does not always do so.

If there is visibility and ignorance, when a partial rational expectations bettor sees the odds change from 20-1 to 12-1 in our example, she will be eager to bet on the temporary-bet horse because the fall in odds reveals information she thinks the opinion bettors will ignore. The partial rational expectations bettor thinks that she can profit by betting against them (namely, betting on the temporarybet horse). Similarly, when the cancellation occurs and odds rise to 14-1, partial rational expectations bettors will shun the temporarybet horse. If there is asymmetry, the money drawn to the temporarybet horse when the bet is made will be larger than the money displaced when the cancellation raises the odds. Assuming visibility, ignorance, asymmetry, and reaction by partial rational expectations bettors therefore implies that the temporary bet will draw more money than the cancellation will displace, so the difference in the bet totals between the temporary-bet horse and the matched control horse at post time will be positive.

iii) Full rational expectations bettors believe that the bet totals contain information but that bet totals at any moment in time fully reflect available information. Unlike the partial rational expectations bettors, who think that they can jump on the bandwagon of a drop in odds and take advantage of ignorant opinion bettors, the full rational expectations bettors think that the odds are always good forecasts. Assume that they therefore bet their money in the same proportion as the proportions already in the bet pool. As a result, when the temporary bet is made, the amount of money full rational expec- 
tations bettors bet on the temporary-bet horse will increase. Indeed, by definition, full rational expectations bettors will keep the odds steady (because they bet in proportions that are the same as those in the pool at the time they bet). In our example, after the temporary bet is made, when the odds are lowered to 12-1, full rational expectations bettors will bet so as to keep the odds at 12-1. When the bet is canceled and the odds hop up to 14-1, full rational expectations bettors will keep the odds steady at 14-1. But since the odds were 20-1 to begin with, the net effect of the temporary bet is to lower the odds by drawing money to the temporary-bet horse. Assuming visibility, ignorance, asymmetry, and reaction by full rational expectations bettors therefore implies that the temporary bet will draw more money than the cancellation will displace, so the difference in bet totals between the temporary-bet horse and the matched control horse at post time will be positive.

If ignorance, visibility, and asymmetry conditions hold, then the direction and strength of the effect depend on the composition of bettors who react. If most bettors (in a dollar-weighted sense) are opinion bettors, the temporary bet will displace money; if bettors are full or partial rational expectations bettors, the bet will draw money. Furthermore, the different types of bettors will react differently after the bet lowers the odds (to 12-1 in our example). Opinion bettors will bet on other horses, gradually raising the odds from 12-1 until the bet is canceled. Partial rational expectations bettors will lower the odds after the bet. (Notice that partial rational expectations bettors can cause a self-fulfilling "mirage" in which a drop from 12-1 to 10-1, say, is misinterpreted as a signal of more information, which triggers further drops.) Full rational expectations bettors will keep the 12-1 odds steady.

The test for an effect of temporary bets is obviously a test of the joint hypotheses of ignorance, visibility, and asymmetry and some specific assumption about the nature of bettors. If there is no effect, since there are good reasons to believe that the ignorance of cancellation and visibility conditions do hold, we can tentatively conclude that either reactions are symmetric or the composition of bettors is such that opposite effects roughly cancel each other out.

\section{Results: Sample 1}

\section{A. An Event Study Look at the Data}

The initial analysis is a kind of "event study" popular in financial economics (see Fama et al. 1969). In an event study, the behavior of market movements around an event $i$ at time $T_{i}$ is aggregated 
across different events $i$. The method is simple: Subtract clock date $T_{i}$ from event $i$, so the time series of events for event $i$ is recoded $-3,-2,-1,0,+1,+2,+3, \ldots$, where 0 now corresponds to "event time" (formerly $T_{i}$ ). Then take statistical measures across events $i$ at equally coded event times. For example, if one wants to know the reactions at the time of the events, compare responses at time 0 . If one wants to know whether people "anticipated" an event, study the negatively numbered times $-4,-3,-2$, and -1 leading up to event time 0 . If one wants to know postevent reactions, study positively numbered times, and so forth.

In this study, a temporary bet is an event. Time is broken up into discrete minutes (when the racetrack "refreshes" the pari-mutuel bet totals). There are three events: The "IN" time, when the bet is made; the "OUT" time, when the bet is canceled; and "post time" (POST), when any net effects of both betting and canceling are measured. The relevant data are bet totals and odds of temporary-bet horses, and matched control horses in the same race, at IN, OUT, and POST times. Reporting relative comparisons controls very effectively for the mutual effects on both the temporary-bet and control horses of, say, unexpectedly heavy betting on a third horse in the same race, which would make the fractions of the totals bet on both the temporary-bet and control horses fall.

\section{B. Effects of Temporary Bets}

Denote the dollar totals bet on the temporary-bet horse, the control horse, and on all horses at time $t$ by $B(t), C(t)$, and $T(t)$. Then the odds on the temporary-bet horse and control horse at $t$ are the fractions $[.85 T(t) / B(t)]-1$ and $[.85 T(t) / C(t)]-1$. The top two lines of figure 2 are the time series of the geometric mean odds of the temporary-bet and control horses, in minutes before post time. The bottom lines show the frequencies of the event times at which bets (INs) and cancellations (OUTs) occurred, ${ }^{6}$ which are shown to indicate when odds movements are expected to occur. (There is substantial variation in the IN times because bets were made at two different tracks, under different conditions.)

Mean odds start around 20-1 for both horses and then dip to nearly $10-1$ on the temporary-bet horses when the bets are made (17-22 minutes to post). The picture confirms that bettors watching the odds board for movements will see a large movement when the temporary bet occurs. Since 20-1 odds imply that roughly 1/20 of the win pool is bet on a horse and an average of $\$ 10,000$ is bet on

${ }^{6}$ The frequencies are actually divided by two to fit underneath the odds paths. 


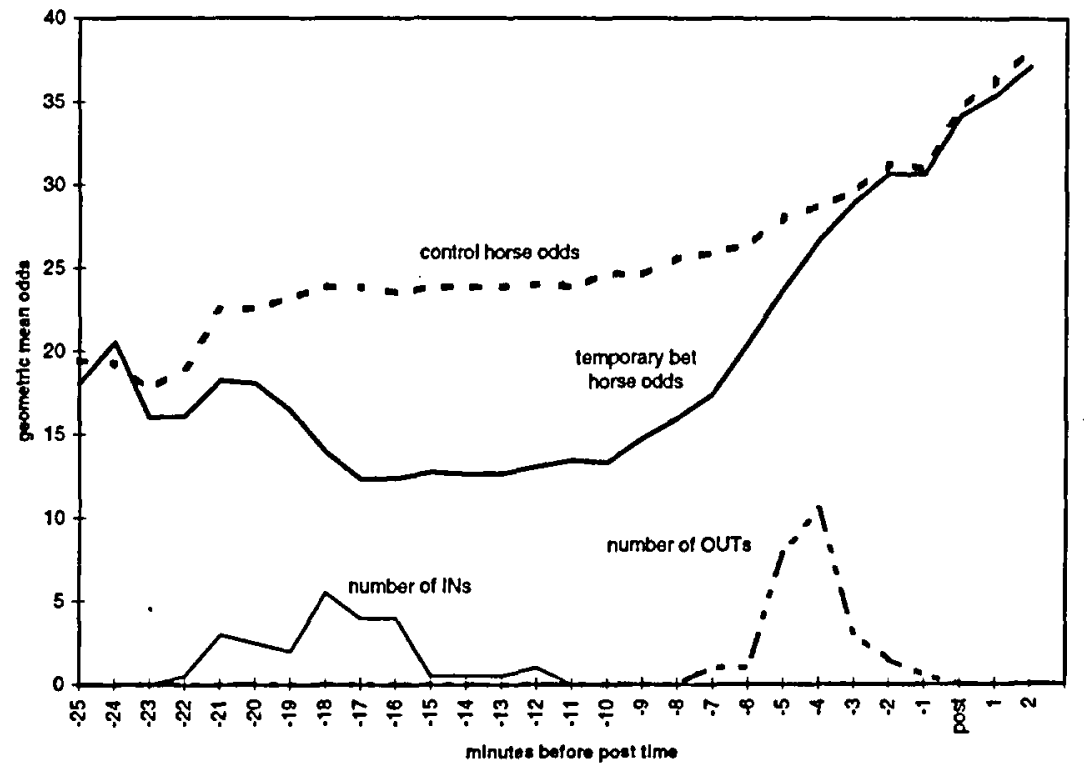

Fig. 2.-Geometric mean odds on temporary-bet horses vs. control horses, sample: 1

all horses when the temporary bets are made, our $\$ 500$ bet roughly doubles the amount of money bet on the temporary-bet horse, cutting the odds in half.

Between minutes -16 and -7 , while the temporary bet is live, the odds creep steadily up on the temporary-bet horse. This is the first clue that temporary bets do not draw much money toward the bet horse. If bettors were betting in proportion to the odds they see during minutes -16 to -7 , the odds on the temporary-bet horse would stay flat rather than creep upward. The upward creep suggests that bettors who are betting during this time are opinion bettors who do not believe that there is much information in odds changes. When the bet is canceled, usually within the -6 - to -4-minute mark, the odds spike sharply upward. The odds on the temporary-bet horse drift a bit further upward after that, but so do the odds on the control horse. Around post time, the odds on temporary-bet horses and matched control horses are very close to equal.

Another way to see the same basic pattern is to track over time the (arithmetic) mean of the absolute dollar differential in the total betting pool for the temporary-bet and control horses, $B(t)-C(t)$. Figure 3 shows the mean (thick line) and the mean plus and minus one standard error (dotted lines) of the dollar bet differential over time. One can see that the temporary bets bump up the money on 


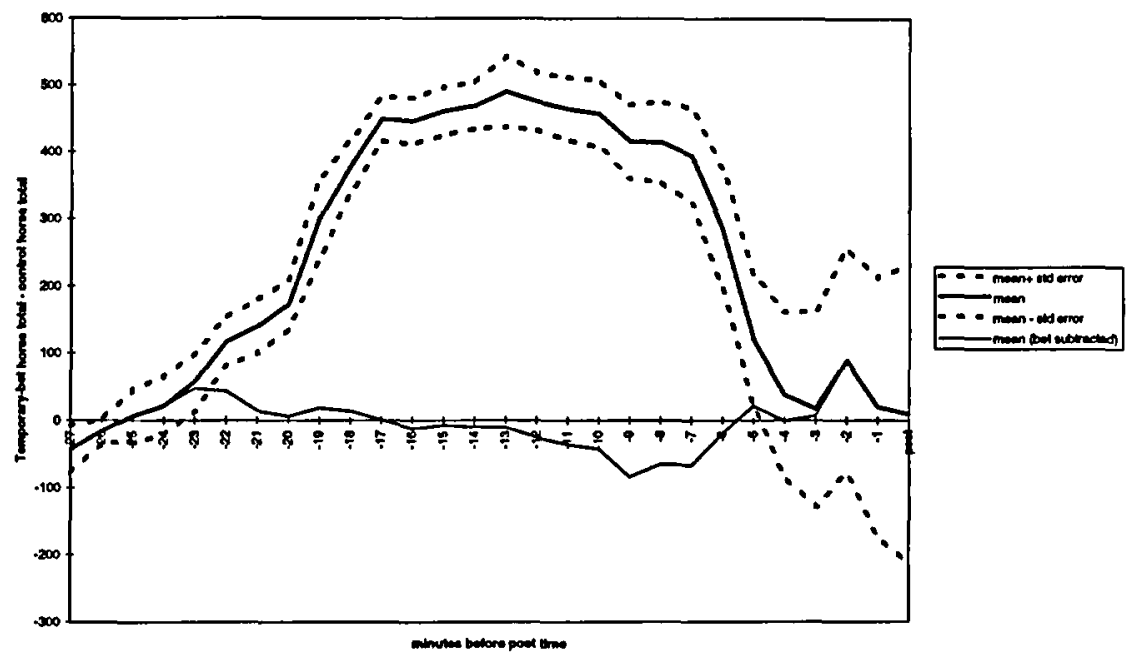

Fic. 3.-Betting differential over time, temporary-bet horse - control horse

the temporary-bet horse by almost $\$ 500$ between minutes -16 and -7 . The fact that the bet differential never quite reaches $\$ 500 \mathrm{im}$ plies that after the bets are made, other bettors begin to bet slightly less on the temporary-bet horse (compared to the control). After the temporary bet is canceled near post time, the dollar differential falls rapidly to zero (with an insignificant blip upward at -2). At post time the differential is very close to zero.

The thin solid line shows the mean differential with the $\$ 500$ bet subtracted back out, to give an indication of whether the effect of the bet was to displace money from the temporary-bet horse (creating a negative differential) or to draw money (creating a positive differential). The mean differential is close to zero throughout, drifts slightly negative while the temporary bet is live, and jumps back toward zero when the bet is canceled. Bars for standard errors are omitted to reduce clutter, but since the standard errors would have the same spread as those around the unadjusted raw mean, a little inspection shows that the bet-subtracted mean is significantly different from zero only at minute -9 .

\section{A Further Look at Temporary Bet-Control Pairs}

The event study time series is a useful way to see the effects of bets and cancellations, but it is not statistically powerful because it does not exploit the fact that each temporary-bet horse is paired with a control. A better look at the data takes each temporary bet and control pair as an observation. Each observation is a pair of num- 


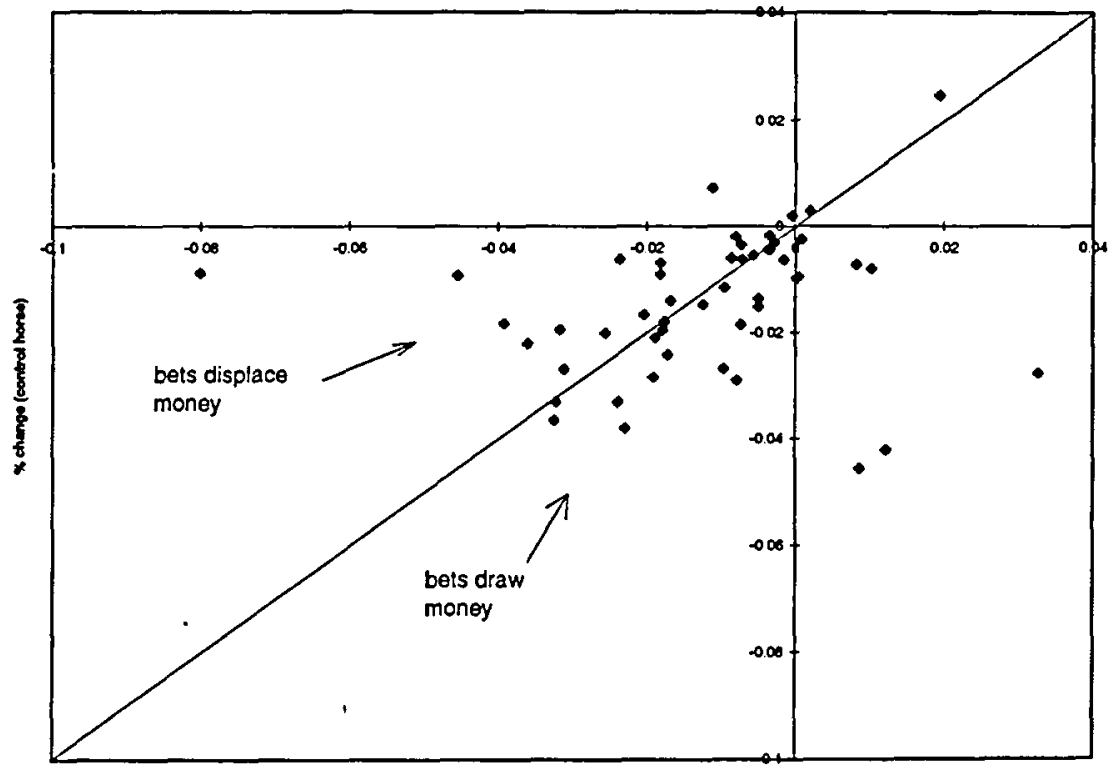

X ehange (lomporery bet hores)

FIG. 4.-Betting changes between POST and IN - 2, temporary bet/control pairs

bers: The first number is the net change in the percentage bet on the temporary-bet horse, measured from 2 minutes before the bet took place, 2 minutes before IN, to post time (denoted $[B(\mathrm{POST}) / T(\mathrm{POST})]-[B(\mathrm{IN}-2) / T(\mathrm{IN}-2)])$. The second number is the analogous net change for the paired control horse, $[C(\mathrm{POST}) / T(\mathrm{POST})]-[C(\mathrm{IN}-2) / T(\mathrm{IN}-2)]$.

Keep in mind that the temporary bet is not reflected in the broadcasted totals at time IN -2 , and the bet has been taken out before post time. Thus the change in net percentage bet between IN -2 and post time reflects only the effects the temporary bet has on other bettors, while the bet was live and between the time it was canceled and post time.

Figure 4 shows a scatter plot of the betting change percentages for the 50 temporary bet-control pairs. Points below the identity line, to the right, indicate a more positive net effect on the temporary-bet horse than on the paired control horse; they represent cases in which money is drawn to the temporary-bet horse by the bet (relative to the control). Points above the identity line, to the left, indicate that the temporary bet displaced or pushed money away.

There are about equally many points above and below the identity line (28 of 50 are above). The means (medians) for the temporary- 
bet and control horse changes are $-.01224(-.00904)$ and -.01434 $(-.0126)$, only about half a standard error from zero. The difference in the two percentages has a mean of .00211 and is insignificant $(t(48)=.74)$. Nonparametric tests do not detect a significant difference either. Figure 4 shows a distinct outlier in the upper left, when the temporary-bet horse fell by .08 and the control by only .01 , making a difference in bet change percentages four standard deviations from the sample mean. Excluding this outlier raises the mean difference between the temporary-bet and control changes to .00360 , which is marginally significant $(t(48)=1.46, p=.15$, two-tailed), but there is no special reason to exclude only this outlier.

It is possible that half the temporary bets push money away and half draw money. If that were so, the mean change in temporarybet horse betting would be no different from the change in control horse betting, but the variance of the betting changes for the temporary-bet horse would be large compared to the variation for the control horse. Looking at figure 4 suggests that this is so-there is more dispersion in betting changes for the temporary-bet horse-but keep in mind that some of the control horses are actually two- and three-horse composites. These composites are averages, so they will naturally have less variance than the single-horse temporary-bet changes. When the standard deviation is adjusted upward appropriately, the sample standard deviation for shifts in bets on the control horse is .01466 , which is insignificantly smaller than the standard deviation for the temporary-bet horse, .01804 by an $F$ test. Thus it appears that the temporary bets do not change the mean amount bet, nor the variance in bet changes, on the temporary-bet horses compared to matched controls.

\section{Within-Bet and Postcancellation Betting Shifts}

While there is no detectable net effect of the temporary bets on betting, it is possible that there is one effect while the bet is ongoing (between the IN and OUT points) and an opposite effect when the bet is canceled, at time OUT.

To check for this, figure 5 shows a scatter plot of temporary-bet and control-bet shifts while the bet is live, between time OUT - 1 (i.e., 1 minute before the bet is canceled) and IN +1 ( 1 minute after it was made). The plotted points are the pairs $\{[B$ (OUT 1) $/ T($ OUT -1$)]-[B(\mathrm{IN}+1) / T(\mathrm{IN}+1)],[C$ (OUT 1) $/ T($ OUT -1$)]-[C($ IN +1$) / T(I N+1)]\}$. The large majority of points lie above the upper left of the identity line. This means that after the temporary bet, the win pool percentage of the tempo- 


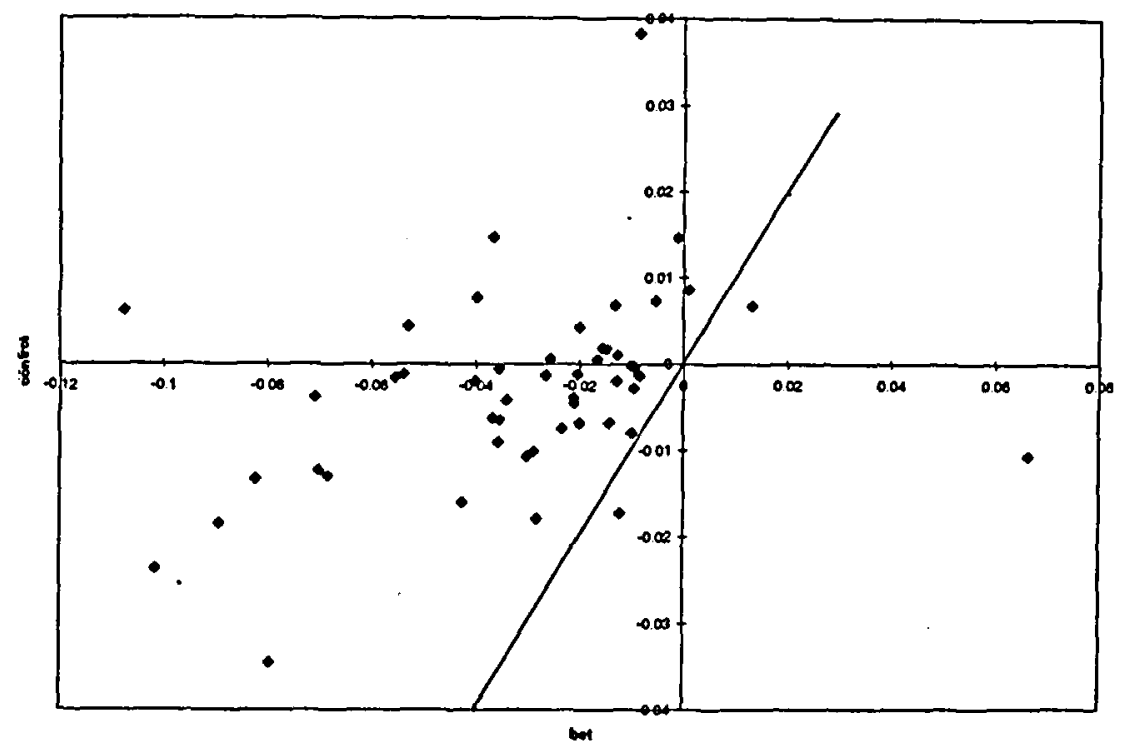

Fic. 5.-Within-temporary-bet shifts, (OUT - 1) - (IN + 1)

rary-bet horse fell more than that of the control horse (recall that figs. 2-3 also showed this effect). Since the win pool is cumulating during this time, this means that the $\$ 500$ bet is not matched by similar infusions of money, so it is shrinking as a percentage of the amount bet on the temporary-bet horse. This means that most bettors who are betting in this time period are some mixture of opinion and full rational expectations bettors.

A similar look at the movement in bet pool percentages between OUT +1 and post time (reported in my working paper [Camerer 1996]) shows no significant difference in changes between the temporary-bet and control horses. Putting the four slices of time together forms a composite picture: When the bet is made, it causes a large bump in the percentage of the total pool bet on the temporary-bet horse (about .04); between the time the bet is made (IN + 1) and the time it is canceled (OUT - 1), the percentage of the pool on the temporary-bet horse shrinks a bit (by about .03) because fans do not continue to bet with the combined proportion of the prebet and $\$ 500$ total. When the $\$ 500$ bet is withdrawn, the percentage falls but by only .01 because the entire bet pool is much larger; after the bet is canceled, no relative movement occurs. Putting these pieces together and recalling the thin flat line from figure 3 , we can see why the temporary bets have no net effect. 


\section{E. Cross-Bet Comparisons}

It may be that temporary bets have no effect on average but do have effects that are predictably related to observables. To check for predictability, I regressed the net temporary-bet effect (the difference in POST minus IN -1 bet shifts between temporary-bet and control horses) against several variables: track location; "manipulability" of the race, measured by the total dollars bet on the attack horse at time IN; and duration of the attack in minutes. A weak positive effect of duration was found $(t=1.39$ when less significant variables were excluded). This positive effect is a little surprising because it means that placing the bet earlier (when its effect on odds is more dramatic, but it might be more likely to be discounted as uninformative) and withdrawing it later seems to help draw money. It may be that canceling very late is important for manipulating the markets. Further experiments could try to exploit this shred of predictability.

\section{Results: Sample 2}

The initial sample shows no substantial net effect of the temporary bets. Given this finding, it seemed sensible to try harder by making bets with more impact. The two dimensions of impact are size and timing: Bets can be larger (as a percentage of the win pool) and made and canceled closer to post time. Bets of this sort are more likely to either appear informative and draw money, or move odds more dramatically and scare away money from opinion bettors (who have less time to adjust and pour money back on the temporary-bet horse after the bets are canceled, if the cancellation is close to post time). To vary impact on these dimensions, 33 more temporary bets were made at smaller racetracks with about a third of the total betting volume of the tracks studied in the first study. Several small changes were made in the design. In the light of the results of the first study, the changes were made with an eye toward giving manipulation its best chance to work.

A total of $\$ 1,000$ was bet. At the time the bet was made, the median total win pool was $\$ 14,003$, so the bets are 7 percent of the win pool. In six cases the bets are more than 20 percent (the maximum is 40 percent).

The bets were made in two separate $\$ 500$ bets. Betting in two waves had some logistical advantages and might fool people into thinking that more than one insider was betting the horse.

Because this second sample is taken from smaller tracks with less betting handle and during an off-peak part of the year when crowds are smaller, it was possible to delay betting until approximately 13 


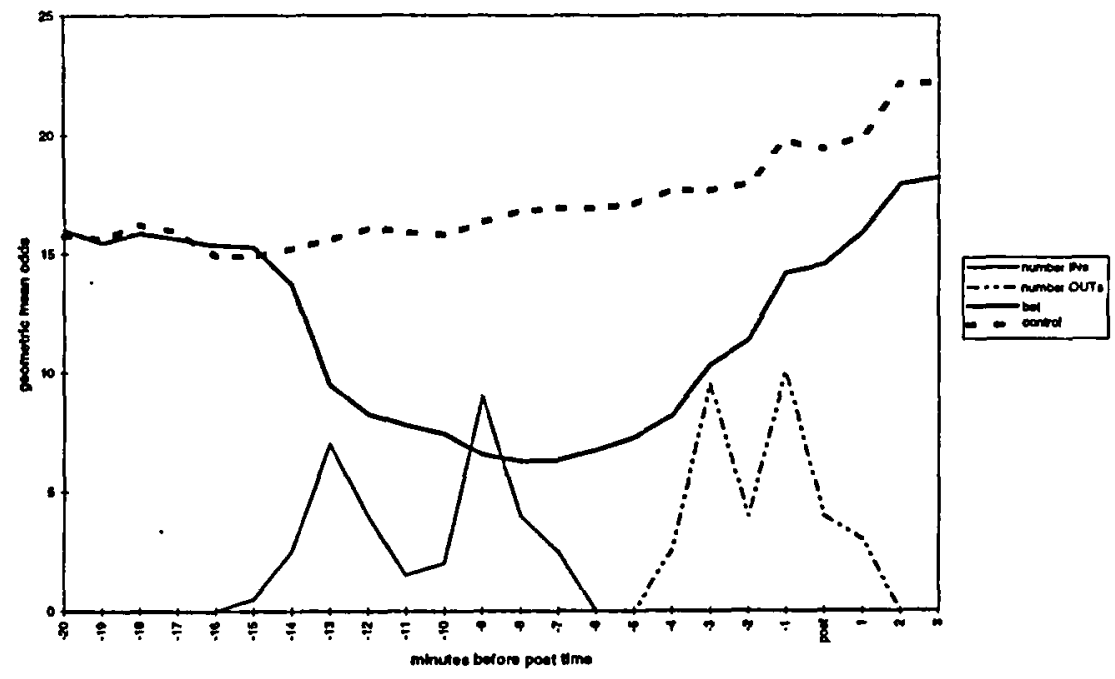

Fic. 6.-Geometric mean odds on temporary-bet vs. control horses, large-bet sample 2.

and 9 minutes before post time. Many bettors think, probably correctly, that better-informed bettors bet later (in order to know more about what odds they will get and to hide their information from the public as long as possible). Hence, by betting later, I might be able to fool more rational expectations bettors into thinking that my bets revealed information.

Because betting lines were short, the bets could be reliably canceled just before post time, at -3 and -1 on average. This too may enhance manipulation by making the effect on the odds of canceling the bet smaller and giving bettors who were earlier drawn toward or away from the temporary-bet horse little time to change their minds.

The results of the 33 bets in this large-bet replication are shown in figure 6. The figure plots the geometric mean odds on temporarybet (thick solid line) and control horses (dotted line) in the $20 \mathrm{~min}$ utes before post time. As in the companion figure 2, the lines at the bottom show the frequency of times at which IN bets (solid line) and OUT cancellations (dotted line) took place. (The IN and OUT frequencies each have two spikes because two $\$ 500$ bets were made in each race.) The initial temporary bet, at around -13, drops the odds from 15-1 to 10-1, and the second temporary bet drops the odds further to around 7-1. There is a small upward drift in the odds on the temporary-bet horse in the gully between the INs and the OUTs, from -7 to -4 , which means that bettors are not drawn 
sufficiently by the temporary bet to keep the odds low (as we saw in sample 1, in fig. 2). After all the OUTs are made, around post time, the odds jump up a bit more; the odds on the control horse rise too. The final odds are slightly lower on temporary-bet horses, about 18-1 versus $22-1$.

Further analysis replicates the basic results from the first sample. The mean change between POST +2 and IN -2 in the percentage bet on the temporary-bet horse is -.00587 ( -.01224 in sample 1$)$, with a standard deviation of .02056 . The corresponding figures for control horses are -.01261 (-.01434 in sample 1) and .0285 (adjusted for composite controls). The mean temporary bet-control bet shift is .006734 , with a standard deviation of $.03128(t(32)=$ $1.23, p=.24)$. The median is .0078 , and 22 of 33 observations are positive. ${ }^{7}$

Pooling these results with the sample 1 results provides weak evidence of a significant positive effect of the temporary bets. The

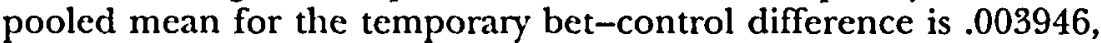
with a standard deviation of .02508 and a $t$-statistic testing for zero mean of $t(82)=1.43(p=.16)$. A conservative sign test -50 of 83 differences are positive-gives $z=1.91(p=.06)$. If there is an effect from these types of temporary bets, it is probably positive, but the magnitude is small enough to still allow the conclusion that manipulating these markets is, if not impossible, certainly not easy.

Two minor effects in the replication sample are notable. "Maiden" races are races for horses that have never won before (and often are racing for the first time). Less is known about these horses, so bettors may watch odds movements more closely for clues about information, and manipulations may be easier. In the replication sample 2 there were 18 maiden races and 15 races for winners. This unusually high percentage of maiden races permits a powerful test for a maiden-race effect. In maiden races, the net temporary-bet effect between IN -2 and POST, relative to the control, is slightly positive (.01294) and weakly significantly larger than in nonmaiden races $(-.01223 ; t(31)=1.22, p=.12$, one-tailed). The effect goes in the sensible direction: Since there is little public information about horses in maiden races, bettors might be more likely to infer information from price movements and bet on horses whose odds drop.

\footnotetext{
${ }^{7}$ An earlier version of this paper (Camerer 1996) reported the first 19 large bets in sample 2; the additional 14 were made to see whether the maiden-nonmaiden difference is robust. Those 19 bets gave temporary-bet minus control percentage changes of -.0045 (mean) and .007 (median). The mean has the opposite sign but is not significantly different from the results in the additional 14 observations. If the difference is genuine, it might be due to betting at much smaller tracks for the additional 14 bets. (For those bets the median total win pool at time -9 was $\$ 6,492$.)
} 
Temporary bets do draw money toward the temporary-bet horse in these races. However, the effect in the original sample is stronger and in the opposite direction: Maiden races have a bet control difference of -.00478 whereas nonmaiden winners have a difference of $.008081(t(41)=-2.318, p=.03)$. Pooling the two samples wipes out both effects.

A more interesting effect arises from the size of the bet pool. While the regression analysis from sample 1 showed no effect of the size of the betting pool, within sample 2 the correlation coefficient of the difference in percentage changes with pool size of bet and control horses (measured by -9 total win bets) is $-.345(t(32)=$ $1.98, p=.05$ ). However, a $t$-test using a median split on pool size, and comparing the bet control differences across below-median and above-median pools, gives means of .0119 (above-median) and .0029 (below-median), with $t(30)=.80$.

These weak effects hold out some slim hope that making temporary bets on maiden races, with small bet pools, could reliably draw money toward the temporary-bet horses. However, one should keep in mind that the sample 2 bets are already quite large. Any racetrack observer would be startled to see the odds on a horse fall by half in one blink of the tote board. The fact that manipulations this large do not generate reliable effects casts doubt on the possibility that even larger bets have effects.

\section{Conclusion}

The answer to my title question is "no." Pari-mutuel racetrack odds could not be systematically manipulated with a sample of $50 \$ 500$ and $33 \$ 1,000$ bets on randomly chosen temporary-bet horses, compared with matched-pair control horses in the same race. There is no evidence during any period-while the bet was "live" and lowered the odds on the bet horse, after it was canceled (raising the odds), or over the entire prebet to postbet period-that other bettors responded systematically to the temporary bets. The bets also did not increase the variance of pre-and postbet changes on the temporary-bet horse, relative to the controls, so it is not the case that temporary bets worked strongly in opposite directions.

One possibility is that these bets were too small, or the markets too large, for the effect of bets to be visible. Larger bets might have different effects. More experiments could conceivably test that possibility, but the $\$ 1,000$ small-pool bets are already quite large. Those bets were 7 percent of the win pool, on average (and frequently up to 20 percent).

Another possibility is that bettors react oppositely to the bet and 
its cancellation and the two effects roughly cancel (violating the asymmetry condition assumed in the theory). This seems unlikely because separate analyses of the within-bet effects (fig. 5) and aftercancellation effects do not show much effect in either period of time. In addition, in the sample 2 replication the time of the bet and its cancellation were delayed substantially, bringing them 2-5 minutes closer to post time. Pushing the betting and cancellation later means that bettors have much less time to react to the cancellation, which should make effects even more asymmetric, but there is little difference between overall effects in samples 1 and 2.

Still another possibility is that markets can be manipulated under some identifiable conditions. There are very weak effects of duration and total bet pool on temporary-bet shifts and weak positive effects in races on nonwinner "maiden" horses (when bettors might be trying to infer information from odds movements more closely) in one sample, but stronger negative effects in another sample. These features may provide clues about how further studies could be designed with a better chance of manipulating markets. In my opinion, it is likely that the duration and maiden-race effects are statistical artifacts that will not replicate, but the ability to draw money through temporary bets in very small win pools may be replicable.

The fact that money is slightly displaced while the temporary bet is live (causing the temporary-bet horse's share of the win pool to fall) but there is no net effect suggests that bettors are some roughly equal (dollar-weighted) combination of opinion and rational expectations bettors. There must be some opinion bettors because if there were only partial and full rational expectations bettors the odds would be steady or would fall after the bet is made, but the odds drift upward instead. And there must be some rational expectations bettors to offset the effect of the opinion bettors, because otherwise total betting on the temporary-bet horse would fall (compared with the control) while the bet is live, which it does not.

Ironically, the slightly stronger positive effect in small bet pools (within sample 2) suggests that there might be relatively more rational expectations bettors at these small "bullring" tracks; in a sense, these bettors are more sophisticated because they take price movements to be informative and react to them a bit more strongly.

Perhaps the most basic conclusion is that these markets simply aggregate information remarkably well, and accordingly, bettors know enough to ignore a large bet that is made far before post time and is not backed up by a steady flow of money, which keeps the heavily bet horse's odds down. How information can aggregate if traders react to signals in opposite ways is a bit of a mystery, but pari-mutuel betting markets are generally considered "surprisingly 
efficient" (Thaler and Ziemba 1988) (although, as in financial markets, painstaking analyses of lots of data have turned up some interesting anomalies that can sometimes be profitably exploited; see, e.g., Hausch and Ziemba [1995]).

To return to the original motivation for this experiment, the inability of these large bets to move the market systematically is a blow to the beliefs of those who think that markets are easily and routinely manipulated by large investors. For those who do not believe that manipulation is common and instead are inclined to marvel at the mysterious collective intelligence of centralized markets populated by self-interested traders, the immunity of these markets to substantial, systematic attempts at manipulation may represent something new to explain, or at least marvel at.

\section{References}

Allen, Franklin, and Gale, Douglas. "Stock-Price Manipulation." Rev. Financial Studies 5, no. 3 (1992): 503-29.

Benabou, Roland, and Laroque, Guy. "Using Privileged Information to Manipulate Markets: Insiders, Gurus, and Credibility." Q.J.E. 107 (August 1992): 921-58.

Camerer, Colin F. "Can Asset Markets Be Manipulated? A Field Experiment with Racetrack Betting." Working Paper no. 983. Pasadena: California Inst. Tech., 1996.

Camerer, Colin F., and Weigelt, Keith. "Information Mirages in Experimental Asset Markets." J. Bus. 64 (October 1991): 463-93.

Dann, Larry Y.; Mayers, David; and Raab, Robert J., Jr. "Trading Rules, Large Blocks and the Speed of Price Adjustment." J. Financial Econ. 4 (January 1977): 3-22.

Duxbury, Darren. "Experimental Asset Markets within Finance." J. Econ. Surveys 9 (December 1995): 331-71.

Fama, Eugene F.; Fisher, Lawrence; Jensen, Michael; and Roll, Richard. "The Adjustment of Stock Prices to New Information." Internat. Econ. Rev. 10 (February 1969): 1-21.

Hausch, Donald B., and Ziemba, William T. "Efficiency in Sports and Lottery Betting Markets." In Finance, edited by Robert A. Jarrow, Vojislav Maksimovic, and William T. Ziemba. Handbooks in Operations Research and Management Science, vol. 9. Amsterdam: North-Holland, 1995.

"New Rules Hit Pro Punters." Auckland Sunday News (August 17, 1997), p. 43.

Nôth, Markus, and Weber, Martin. "Insider Detection in Experimental Asset Markets." Manuscript. Mannheim: Lehrstūhle für Finanzwirtschaft, 1996.

Plott, Charles R., and Sunder, Shyam. "Efficiency of Experimental Security Markets with Insider Information: An Application of Rational-Expectations Models." J.P.E. 90 (August 1982): 663-98.

Plott, Charles R.; Wit, Jörgen; and Yang, C. Winston. "Parimutuel Betting Markets as Information Aggregation Devices: Experimental Results." Manuscript. Pasadena: California Inst. Tech., 1996. 
Scholes, Myron S. "The Market for Securities: Substitution versus Price Pressure and the Effects of Information on Share Prices." J. Bus. 45 (April 1972): 179-211.

Sunder, Shyam. "Market for Information: Experimental Evidence." Econometrica 60 (May 1992): 667-95.

-. "Experimental Asset Markets: A Survey." In The Handbook of Experimental Economics, edited by John Kagel and Alvin E. Roth. Princeton, N.J.: Princeton Univ. Press, 1995.

Thaler, Richard H., and Ziemba, William T. "Parimutuel Betting Markets: Racetracks and Lotteries." J. Econ. Perspectives 2 (Spring 1988): 161-74. 